http://dx.doi.org/10.1590/1678-4162-7921

Arq. Bras. Med. Vet. Zootec., v.68, n.1, p.119-126, 2016

\title{
Pinealectomia em ratas Wistar (Rattus norvegicus albinus): descrição de um novo método cirúrgico
}

[Pinealectomy in Wistar rats (Rattus norvegicus albinus): Description of a new surgical method]

\author{
F.R.N.F. Burgos, J.L.S. Lima, E.L. Almeida, L.G.P. Santos, V.A. Silva Júnior
}

Universidade Federal Rural de Pernambuco - Recife, PE

\begin{abstract}
RESUMO
A necessidade de manejo adequado antes, durante e após a implementação de procedimentos em animais de laboratório é essencial para proporcionar bem-estar. Portanto, no presente trabalho, objetivou-se padronizar uma nova técnica de pinealectomia em ratas Wistar. Trinta fêmeas nulíparas aos 90 dias de idade foram submetidas à anestesia dissociativa. Após a tricotomia e a assepsia, realizou-se uma incisão na linha média dorsal da cabeça. Com um micromotor e uma broca de aço PM 03, realizou-se a craniotomia; a glândula pineal foi removida por intermédio de um fórceps cápsula arruga. Em seguida, o fragmento ósseo foi recolocado em seu lugar de origem, e a pele aproximada por pontos simples. Finalizado o procedimento cirúrgico, foi realizada antibioticoterapia e soroterapia parenteral. $\mathrm{O}$ acompanhamento diário dos animais não evidenciou nenhum comprometimento da ferida operatória com padrão de cicatrização por primeira intenção. Os animais apresentaram normalidade de atos fisiológicos, como alimentação, defecação e micção, assim como socialização com o grupo. Técnicas cirúrgicas vêm sendo realizadas com o desenvolvimento das pesquisas envolvendo a glândula pineal. A técnica ideal para pinealectomia consiste no pouco sangramento, na curta duração da cirurgia e na nitidez da glândula pineal, diminuindo a probabilidade de acidentes neurológicos. Considerando-se os resultados obtidos ao longo do desenvolvimento experimental e clínico, o aprimoramento da técnica cirúrgica utilizando a broca PM03 associada ao fórceps cápsula arruga foi exímio na pesquisa científica da pinealectomia de ratas Wistar em virtude da rapidez e praticidade alcançadas. Tem-se a perspectiva de que este artigo sirva de subsídio para o aprimoramento e a otimização do modelo experimental para posteriores estudos acerca de pesquisas com a glândula pineal e, assim, maior compreensão de sua complexidade sobre todos os sistemas do organismo.
\end{abstract}

Palavras-chave: glândula pineal, procedimento cirúrgico operatório, inovação

\begin{abstract}
The need for adequate management before, during and after procedures involving laboratory animals is essential to their wellbeing. Thus, the aim of the present study was to standardize a novel method of pinealectomy in Wistar rats. Thirty nullipara females aged 90 days were submitted to dissociative anesthesia. Following fur removal and asepsis, an incision was performed along the dorsal line of the head. Craniotomy was performed with a mini-drill and PM 03 stainless steel drill bit. The pineal gland was removed using a serrated capsule forceps. The bone fragment was replaced and the skin was sutured with simple stitches. The surgical procedure was finalized with antibiotic therapy parenteral serotherapy. Daily follow up was performed and no animal demonstrated any compromised surgical wound with first intention wound healing. The animals exhibited normal physiological acts (feeding, defecation, urination and group socialization). Surgical techniques were performed with the development of research involving the pineal gland. The ideal pinealectomy method consists of little bleeding, a short surgery and a clear view of the pineal gland, thereby diminishing the probability of neurological accidents. Considering the results obtained through the experimental and clinical development, the perfection of the surgical technique involving the PM03 drill bit and serrated capsule forceps was successful in scientific research
\end{abstract}

Recebido em 20 de agosto de 2014

Aceito em 17 de agosto de 2015

E-mail: frfabia@hotmail.com 
involving pinealectomy of Wistar rats in terms of quickness and practicality. This article can assist in the optimization of experimental models for subsequent studies involving the pineal gland and the understanding of its complexity over all organism systems.

Keywords: pineal gland, surgical procedures operative, innovation

\section{INTRODUÇÃO}

A glândula pineal (em forma de pinha) é uma pequena glândula endócrina fixada ao teto do terceiro ventrículo do encéfalo, na linha mediana (Tortora e Derrickson, 2012). Localiza-se abaixo do corpo caloso e, diferentemente das outras glândulas, é controlada pelo núcleo supraquiasmático, situado no hipotálamo, considerado o principal relógio biológico dos mamíferos (Reiter et al., 1989).

De origem neuroectodérmica, esse pequeno apêndice encefálico mediano é uma minúscula glândula endócrina que produz a melatonina. Acredita-se que esse derivado da serotonina ou de algum mediador relacionado, semelhante a um hormônio, exerça um efeito supressivo na secreção de gonadotrofinas e, por isso, iniba o crescimento e a função das gônadas (Cormack, 2008). A pinealectomia, remoção cirúrgica da glândula pineal, em modelos de roedores, acelera o crescimento e o aumento da incidência de cânceres experimentais (Das Gupta e Terz, 1967).

Andersen e Wolf (1934), além de realizem experimentos com ratos pinealectomizados, descreveram um estudo crítico da literatura com os primeiros estudos do procedimento cirúrgico em cachorro, ratos, cobaias, coelho, pintinho e sapo, desde a primeira década do século passado.

Com o desenvolvimento das pesquisas envolvendo a glândula pineal, procedimentos cirúrgicos vêm sendo realizados (Tab. 1). É de se reconhecer, na maioria dos casos, o problema da rápida hemorragia de forma fatal envolvendo os seios da duramáter. A técnica ideal para remoção da pineal deve-se ao estancamento do sangramento, à curta duração da cirurgia, à apresentação de uma visão clara da glândula pineal no local da operação, facilitando a sua extirpação e diminuindo a probabilidade de danos acidentais nas estruturas neurais adjacentes (Kuszak e Rodin, 1977).

Tabela 1. Histórico dos principais autores que descreveram técnicas de pinealectomia de 1934 a 2009

\begin{tabular}{|c|c|c|c|c|c|c|c|}
\hline Autor & Ano & $\begin{array}{c}\text { Número } \\
\text { de } \\
\text { animais }\end{array}$ & Craniotomia & Broca & Pinealectomia & $\begin{array}{l}\text { Fios para os } \\
\text { seios venosos }\end{array}$ & $\begin{array}{l}\text { Fios para } \\
\text { a pele }\end{array}$ \\
\hline $\begin{array}{l}\text { Andersen e } \\
\text { Wolf }\end{array}$ & 1934 & 125 & Quadrado & Lanceta & Pinça & Não ligou & $\begin{array}{c}\text { Sem } \\
\text { descrição }\end{array}$ \\
\hline $\begin{array}{l}\text { Das Gupta } \\
\text { e Terz }\end{array}$ & 1967 & 114 & Quadrado & Circular & $\begin{array}{l}\text { Pinça de } \\
\text { relojoeiro }\end{array}$ & $7-0$ seda & $\begin{array}{c}\text { Catgut } \\
\text { cromado 4-0 }\end{array}$ \\
\hline $\begin{array}{l}\text { Kuszak e } \\
\text { Rodin }\end{array}$ & 1977 & 200 & Retangular & $\begin{array}{c}\text { Broca } \\
n^{\circ} 05\end{array}$ & $\begin{array}{l}\text { Pinça de } \\
\text { relojoeiro e } \\
\text { estereotáxico } \\
\text { D. Kopf, } \\
\text { Tujunga, Ca }\end{array}$ & $\begin{array}{c}\text { Fio cirúrgico } \\
6-0\end{array}$ & $\begin{array}{c}\text { Clipes de } \\
\text { ferida Michel }\end{array}$ \\
\hline $\begin{array}{l}\text { Evêncio- } \\
\text { Neto }\end{array}$ & 1998 & 36 & Circular & $\begin{array}{l}\text { Tronco- } \\
\text { cônica }\end{array}$ & $\begin{array}{l}\text { Lupa e pinça } \\
\text { de relojoeiro }\end{array}$ & Catgut 5-0 & $\begin{array}{c}\text { Polipropileno } \\
3-0\end{array}$ \\
\hline $\begin{array}{l}\text { Soares } \\
\text { Júnior et } \\
\text { al. }\end{array}$ & 1999 & 20 & $\begin{array}{c}\text { Sem } \\
\text { descrição }\end{array}$ & Circular & $\begin{array}{c}\text { Pinça } \\
\text { apropriada e } \\
\text { estereotáxico }\end{array}$ & $\begin{array}{c}\text { Sem } \\
\text { descrição }\end{array}$ & $\begin{array}{c}\text { Sem } \\
\text { descrição }\end{array}$ \\
\hline $\begin{array}{l}\text { Maganhin } \\
\text { et al. }\end{array}$ & 2009 & 80 & Circular & $\begin{array}{c}\text { Sem } \\
\text { descrição }\end{array}$ & $\begin{array}{c}\text { Lupa e pinça } \\
\text { curva }\end{array}$ & $\begin{array}{c}\text { Catgut } \\
\text { simples 5-0 }\end{array}$ & $\begin{array}{c}\text { Polipropileno } \\
3-0\end{array}$ \\
\hline
\end{tabular}

Este trabalho propõe a padronização de uma nova técnica, mediante a utilização de um instrumento cirúrgico adaptado e fio absorvível ABSPoliglactina $^{\circledR}$ (PGLA), para a pinelatectomia em ratas Wistar.

\section{MATERIAL E MÉTODOS}

Todos os procedimentos experimentais envolvendo a utilização de animais foram aprovados pela Comissão de Ética no Uso de 


\section{Pinealectomia em ratas...}

Animais (CEUA) da Universidade Federal Rural de Pernambuco (UFRPE) (Licença $\mathrm{N}^{\mathrm{o}}$ 026/2012). As ratas Wistar (Rattus norvegicus albinus) nulíparas aos 90 dias de idade, eram adultas jovens, passíveis de suportar um procedimento cirúrgico. Pesando aproximadamente $227 \mathrm{~g}$, foram provenientes do Biotério do Departamento de Morfologia e Fisiologia Animal (DMFA) da UFRPE. As intervenções cirúrgicas e as observações foram realizadas pelo período de maio a setembro de 2012. Todos os animais foram operados e avaliados clinicamente nos 30 dias pós-cirúrgico.

As ratas Wistar foram distribuídas aleatoriamente em grupos formados por seis animais, e cada grupo foi acondicionado em gaiolas de policarbonato com tampa gradeada de metal e forradas com maravalha de pinus. As ratas Wistar foram expostas a fotoperíodo de 12 horas de luz artificial produzida por lâmpadas fluorescentes, e por 12 horas de escuridão, com acesso a água e ração (Labina para roedores Purina $^{\circledR}$ ) ad libitum e a temperatura e a umidade do ambiente controladas (Harkness e Wagner, 1993).

Trinta fêmeas clinicamente sadias foram submetidas à anestesiada dissociativa com cloridrato de xilazina a $2 \% \quad(10 \mathrm{mg} / \mathrm{kg} / \mathrm{IM})$ $\left(\right.$ Anasedan $\left.^{\circledR}\right)$ e cloridrato de cetamina $(75 \mathrm{mg} / \mathrm{kg} / \mathrm{IM}) \quad\left(\right.$ Vetanarcol $\left.^{\circledR}\right)$, mantidas sob respiração espontânea. As ratas Wistar foram posicionadas em decúbito ventral sob cama cirúrgica adaptada com seus membros em extensão. Procedeu-se à tricotomia com lâmina de aço inoxidável e à assepsia da área dorsal da cabeça com digluconato de clorexidina a $2 \%$ $\left(\right.$ Handex $\left.^{\circledR}\right)$ e solução fisiológica de cloreto de sódio a $0,9 \%{ }^{\circledR}$ (Fig. 1).

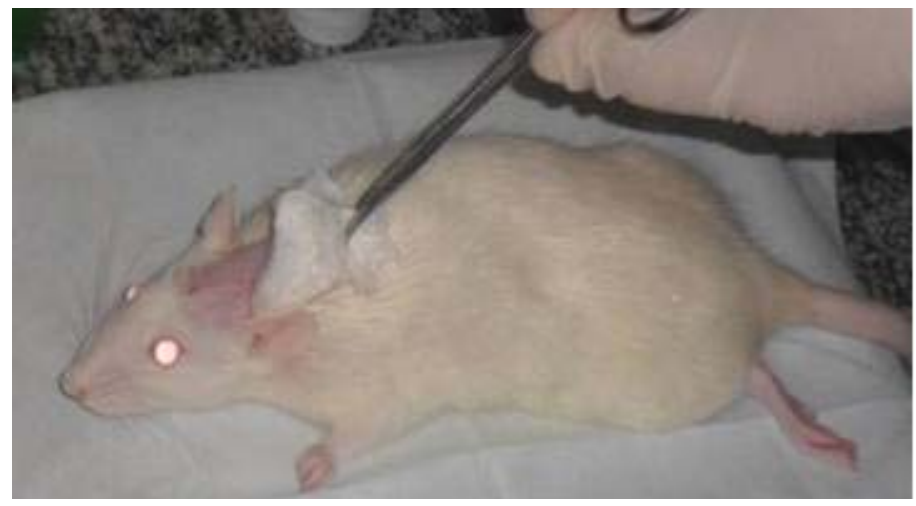

Figura 1. Rata. Fotografia mostrando o animal em decúbito ventral, evidenciando a área cirúrgica após tricotomia e assepsia.

Procedeu-se à colocação dos campos cirúrgicos, limitando a área operatória. Realizou-se, com bisturi $n^{\circ} 04$ e lâmina $n^{\circ} 22$, uma incisão de $2 \mathrm{~cm}$ na linha média dorsal da cabeça desde a região interorbitária até a região interauricular (Fig. 2). As abas de pele foram rebatidas e assim mantidas.

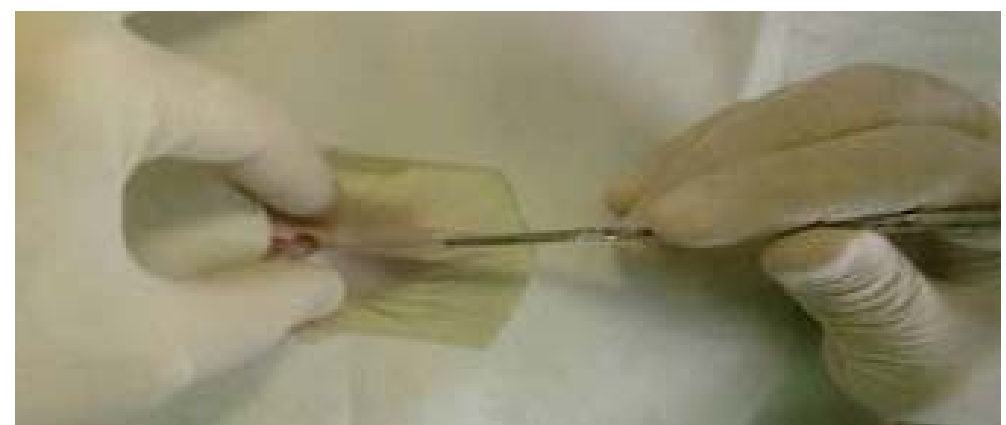

Figura 2. Rata. Fotografia demonstrando a realização da incisão com o bisturi na linha média dorsal desde a região interorbitária até a região interauricular. 


\section{Burgos et al.}

Com um micromotor (Motor de Suspensão Beltec Mini) de baixa rotação (RPM 15.000) e uma broca odontológica de aço PM 03 acoplada a um mandril, realizou-se a craniotomia (Fig. 3). Retirou-se um fragmento circular da calota de aproximadamente $4 \mathrm{~mm}$ de diâmetro, tendo como ponto central de referência o lambda, ou seja, a união da sutura sagital com a sutura lambdoidea. Tomou-se o cuidado de iniciar o procedimento na região cranial direita no osso frontal, seguido do parietal, passando para o lado esquerdo; procedeu-se às incisões dos ossos frontal $\mathrm{e}$ parietal, e finalmente o osso occipital. Assim, diminuíram-se os riscos de lesões encefálicas, pois o osso occipital apresenta maior resistência e localiza-se numa região de difícil acesso.

As suturas cranianas foram seccionadas sempre após todos os ossos craniais, em virtude da grande vascularização no local, o que dificulta a visualização da área cirúrgica e aumenta o risco de morte. Após a retirada do fragmento ósseo, este foi acondicionado em recipiente contendo solução fisiológica de cloreto de sódio a $0,9 \%$.

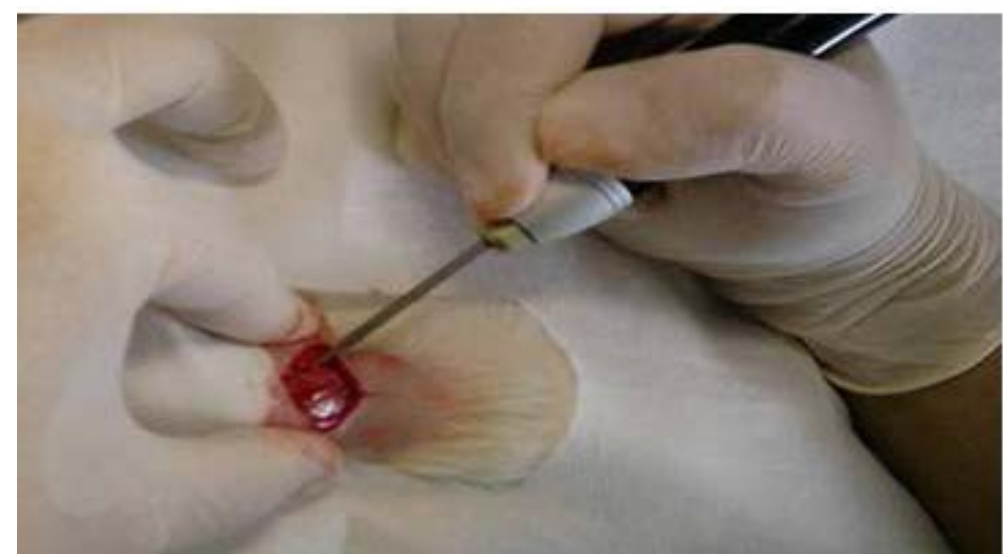

Figura 3. Rata. Fotografia evidenciando a craniotomia com auxilio do micromotor de baixa rotação e broca de aço PM 03.

Tendo a visibilização da junção dos seios venosos - sagital superior e transverso em forma de Y (Fig. 4) -, dois fios de sutura 5-0 ABSPoliglactina $^{\circledR}$ (PGLA) foram transfixados delicadamente, um próximo à confluência dos seios e o outro mais afastado desse ponto, de modo que, uma vez tracionados, obteve-se a ligadura desse seio.

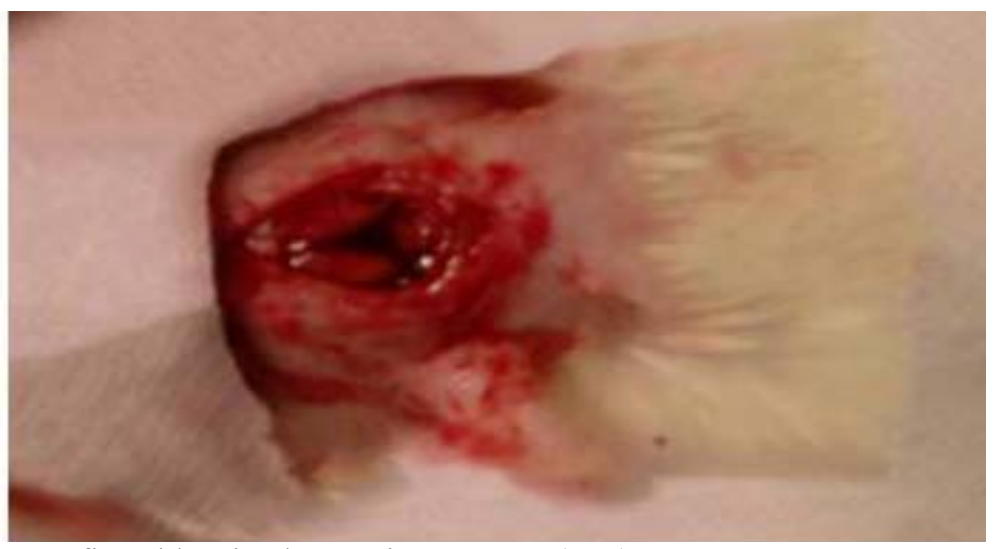

Figura 4. Rata. Fotografia evidenciando os seios venosos (seta).

Com o uso de uma tesoura cirúrgica reta romba $12 \mathrm{~cm}$, procedeu-se a uma secção do vaso entre os dois nós e, logo após, o nó próximo à confluência foi flexionado para visualização e retirada da glândula pineal por intermédio de um fórceps cápsula arruga de $9,5 \mathrm{~cm}$; a glândula foi fixada em glutaraldeído. A hemostasia em leito era feita por compressão digital, utilizando-se 


\section{Pinealectomia em ratas...}

algodão odontológico umedecido em solução salina a $0,9 \%{ }^{\circledR}$. Em seguida, o fragmento ósseo foi recolocado sem fixação e recoberto com pele suturada em pontos simples com fio 5-0 ABSPoliglactina ${ }^{\circledR}$ (PGLA).

Como medida de prevenção de infecção póscirúrgica, foi administrada uma única dose de $10 \mathrm{mg} / \mathrm{kg}$ subcutâneo de sulfa + trimetropim $\left(\right.$ Dimetoprim $\left.^{\circledR}\right)$. Como reposição hidroeletrolítica imediata, foram administrados $2 \mathrm{~mL}$ de solução fisiológica de cloreto de sódio a $0,9 \%{ }^{\circledR}$ subcutâneo. Posteriormente, os animais foram mantidos por 20 minutos em manta térmica e recolocados em suas gaiolas após assepsia (Fig. 5). Os animais permaneceram em observação até a recuperação anestésica, avaliada pelo retorno dos reflexos abolidos e pela movimentação ativa e/ou estimulada na gaiola. Durante 30 dias, os animais foram examinados quanto ao seu estado geral (Fig. 6).

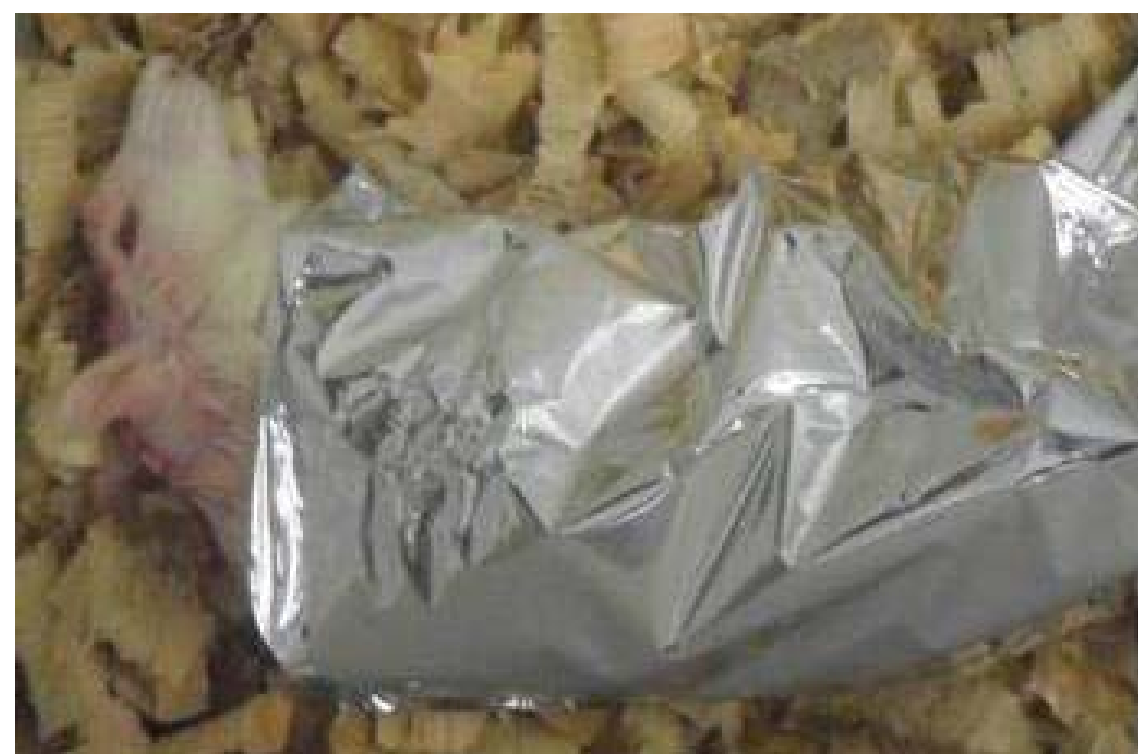

Figura 5. Rata. Pós-operatório. Fotografia mostrando animal envolvido por uma manta térmica.

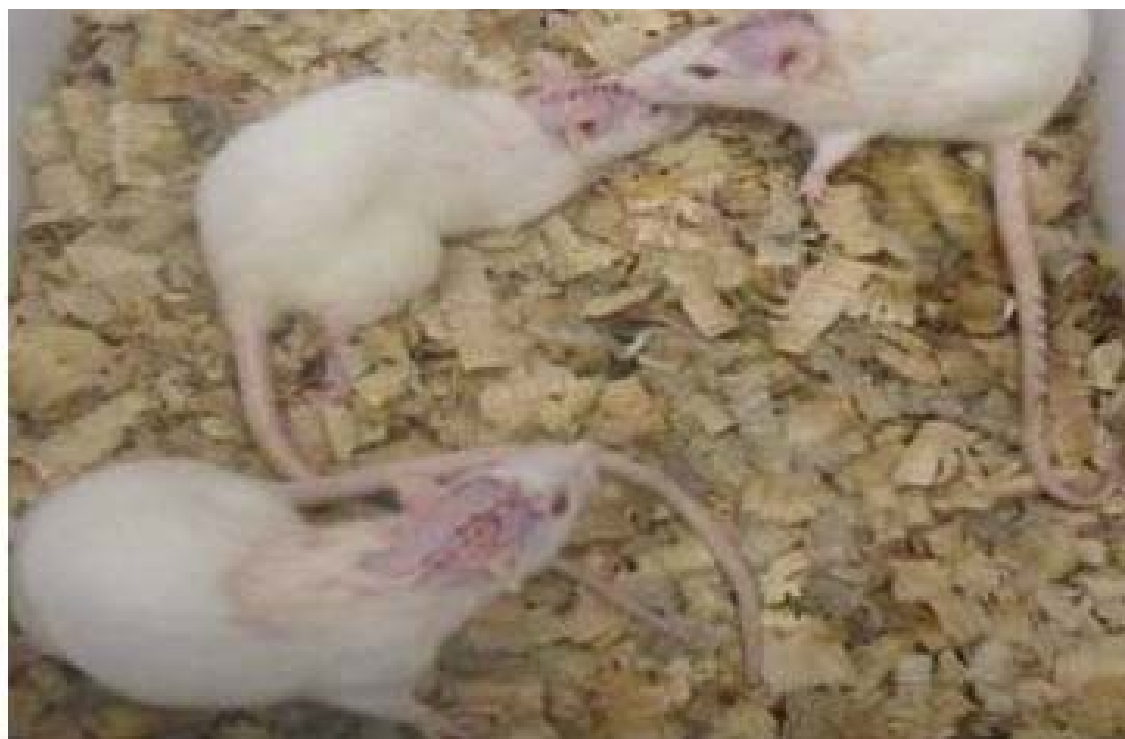

Figura 6. Rata. Fotografia evidenciando a recuperação anestésica dos animais, avaliada pelo retorno dos reflexos abolidos e pela movimentação ativa e/ou estimulada na gaiola. 


\section{RESULTADOS E DISCUSSÃO}

As ratas Wistar utilizadas apresentaram-se dóceis, de fácil manipulação e tiveram recuperação rápida do efeito dos anestésicos. Constituíram uma amostra muito homogênea, proveniente do Biotério do Departamento de Morfologia e Fisiologia Animal. De acordo com Massone (1994b), a escolha do animal a ser empregado em experimentação científica é importante, pois é necessário que se levem em consideração a praticidade de manipulação, o tipo de ensaio biológico e o custo operacional.

O acompanhamento diário dos animais não evidenciou nenhum comprometimento da ferida operatória com padrão de cicatrização por primeira intenção. Os animais apresentaram normalidade de atos fisiológicos, como alimentação, defecação e micção, assim como socialização com o grupo. Os achados mostraram que, de modo indireto, o ato operatório não afetou o bem-estar e o estado geral dos animais. A padronização de um novo procedimento cirúrgico para a pinealectomia foi eficaz no que se refere à ausência de óbitos durante o procedimento da pinealectomia (Tab. 2).

Tabela 2. Relação entre animais operados e número de óbitos observados no período de maio a setembro de 2012

\begin{tabular}{ll}
\hline Animais & Número \\
\hline Operados & $30(100 \%)$ \\
Vivos & $30(100 \%)$ \\
Óbitos & $0(0 \%)$ \\
\hline
\end{tabular}

No tocante ao procedimento anestésico empregado, as ratas Wistar foram submetidas à anestesia dissociativa, com $10 \mathrm{mg} / \mathrm{kg}$ intramuscular de cloridrato de xilazina a $2 \%$ $\left(\right.$ Anasedan $^{\circledR}$ ) e $75 \mathrm{mg} / \mathrm{kg}$ intramuscular de cloridrato de cetamina $\left(\right.$ Vetanarcol $\left.{ }^{\circledR}\right)$, o que permitiu realizar convenientemente todas as manobras cirúrgicas e todas as ratas Wistar apresentaram boa recuperação pós-operatória. Conforme Massone (1994b), bons resultados em anestesia em ratos foram obtidos a pelas associações anestésicas entre um agente dissociativo (quetamina) e uma droga de ação miorrelaxante, analgésica e sedativa (xilazina), características de neuroleptoanalgesia. Massone (1994a) acrescentou que essa associação tem se consagrado devido à praticidade, pois o próprio cirurgião efetua a anestesia com dose única e por via intramuscular, além de o paciente permanecer com os reflexos protetores presentes e o período anestésico ser hábil.

Para uma assepsia eficaz, utilizaram-se digluconato de clorexidina a $2 \%$ e solução fisiológica de cloreto de sódio a $0,9 \%$, para então colocação do campo cirúrgico, atitudes que minimizam os riscos de meningite bacteriana. Não foi necessária a fixação da cabeça do animal ao aparelho estereotáxico para proceder à pinealectomia, como em Kuszak e Rodin (1977) e Soares Júnior et al. (1999).

Após o afastamento da pele, Kuszak e Rodin (1977) e Evêncio-Neto (1998) realizaram a raspagem do periósteo expondo a sutura occipitointerparietalis; no entanto, em virtude da importância desse tecido na ossificação, tal procedimento foi descartado e, em necropsia de um animal aos 15 dias pós-cirúrgico, verificou-se a consolidação óssea da calota craniana.

A forma esférica da broca de aço PM 03 acoplada a um mandril para a craniotomia evita lesões no encéfalo. Por possuir menor diâmetro, torna-se mais delicada para o procedimento, dando maior destreza e controle na cirurgia. Evêncio-Neto (1998) realizou a craniotomia com broca cônica, que, devido a sua ponta cônica, facilita as perfurações encefálicas. Das Gupta e Terz (1967) e Soares Júnior et al. (1999) utilizaram uma broca circular que também requer muita habilidade do cirurgião.

Retirou-se um fragmento circular da calota de aproximadamente $4 \mathrm{~mm}$ de diâmetro de forma semelhante a Evêncio-Neto (1998) e Maganhin et al. (2009), diferente de Kuszak e Rodin (1977), que realizaram incisão retangular; Andersen e Wolf (1934) e Das Gupta e Terz (1967) procederam a uma craniotomia de forma quadrangular. Após a retirada do fragmento ósseo, este foi acondicionado em um recipiente contendo solução fisiológica de cloreto de sódio a $0,9 \%$, ao contrário do procedimento realizado por Evêncio-Neto (1998), em que o fragmento ósseo foi retirado e mantido sobre algodão umedecido em solução salina a $0,9 \%$.

O fio não absorvível pode agir como corpo estranho, dificultando a cicatrização e provocando alterações dolorosas na área cirúrgica, além de lesões encefálicas, o que 
prejudica o estado geral do animal no pósoperatório. As ratas Wistar responderam muito bem ao fio absorvível ABSPoliglactina ${ }^{\circledR}$ (PGLA) na ligadura dos seios venosos, com ausência de reações tipo corpo estranho ou de eliminação. Entretanto, no trabalho de Evêncio-Neto (1998), foi usado o fio catgut 5-0 simples; já Kuszak e Rodin (1977) utilizaram fio cirúrgico 6-0; Maganhin et al. (2009) lançaram mão do catgut simples 5-0, e Das Gupta e Terz (1967) realizaram todos a ligadura desses seios venosos com fio de seda 7-0. Todos os autores também obtiveram bons resultados.

Interessantemente, Andersen e Wolf (1934) não ligaram os seios venosos, provavelmente devido à idade dos animais utilizados em seu experimento, pois se tratou de ratas com um a três dias de idade. A tesoura cirúrgica reta romba foi utilizada com sucesso na secção do fio entre os dois nós que ligaram os seios venosos, sem a necessidade da tesoura de íris, como em Evêncio-Neto (1998).

A pinça de relojoeiro utilizada por Das Gupta e Terz (1967), Kuszak e Rodin (1977) e EvêncioNeto (1998) foi substituída com sucesso pelo fórceps cápsula arruga, em cuja cavidade a glândula pineal foi acoplada e removida por tensão de maneira direta e rápida, sem produzir alterações encefálicas e sem a necessidade da lupa estereoscópica, como em Evêncio-Neto (1998) e Maganhin et al. (2009), e de um estereotáxico, como utilizado por Kuszak e Rodin (1977) e Soares Júnior et al. (1999). Essas manobras foram de extrema importância para um melhor procedimento cirúrgico, pois os animais não precisaram ser acomodados em equipamentos específicos, evitando traumas.

Não foram observadas reação ao fio ou descência de pontos na pele com aproximação das bordas cirúrgicas com o fio absorvível ABSPoliglactina $^{\circledR}$ (PGLA) utilizado. Outro tipo de fio absorvível, Catgut cromado 4-0, já foi utilizado em 1967 por Das Gupta e Terz também com bons resultados. Evêncio-Neto (1998) e Maganhin et al. (2009), utilizaram o fio não absorvível polipropileno 3-0, e Kuszak e Rodin (1977) utilizaram dois clipes de feridas $11 \mathrm{~mm}$ Michel, todos com ausência de problemas com a cicatrização.
Em virtude do tamanho da área operatória e do fato de se tratar de uma região altamente sensível, optou-se por realizar a hemostasia em leito com algodão odontológico, umedecido em solução fisiológica a $0,9 \%$, que é extremamente absorvível e possui uma proteção externa que impede a perda de fios, em contrapartida o uso de gaze também umedecida foi descrito por Evêncio-Neto (1998).

Soares Júnior et al. (1999) e Maganhin et al. (2009) realizaram a profilaxia contra infecções no pós-operatório da pinealectomia com a administração de pentabiótico, aquele na dosagem de $0,4 \mathrm{~mL}$ por animal, e este de $570 \mathrm{mg} / \mathrm{kg}$ subcutâneo, por via intramuscular. No entanto, no presente estudo, administrou-se sulfa + trimetoprim, em dose única, no pós-operatório imediato.

\section{CONCLUSÕES}

Considerando os resultados obtidos ao longo do desenvolvimento experimental e clínico, o aprimoramento da técnica cirúrgica utilizando a broca PM03 associada ao fórceps cápsula arruga foi exímio na pesquisa científica da pinealectomia de ratas Wistar em virtude da rapidez e da praticidade alcançadas. Tem-se a perspectiva de que este artigo sirva de subsídio para o aprimoramento e a otimização do modelo experimental para posteriores estudos acerca de pesquisas com a glândula pineal e, assim, maior compreensão de sua complexidade sobre todos os sistemas do organismo.

\section{REFERÊNCIAS}

ANDERSEN, D.H.; WOLF, A. Pinealectomy in rats with a critical survey of the literature. $J$. Physiol., v.81, p.49-62, 1934.

CORMACK, D.H. (Ed). Sistema endócrino. In: Fundamentos de histologia. Rio de Janeiro: Guanabara Koogan, 2008. p.299-315.

DAS GUPTA, T.K.; TERZ, J. Influence of pineal gland on the growth and spread of melanoma in the hamster. Cancer Res., v.27, p.1306-1311, 1967. 
EVENCIO-NETO, J. Efeito da melatonina na adrenal de ratas pinealectomizadas. 1998. 54f. Tese (Doutorado em Técnica Operatório e Cirurgia Experimental) - Escola Paulista de Medicina, Universidade Federal de São Paulo, São Paulo, SP.

HARKNESS, J.E.; WAGNER, J.E. (Eds.). Biologia e clínica de coelhos e roedores. In: $\overline{p .9-55}$.

Biologia e manejo. São Paulo: Roca, 1993.

KUSZAK, J.; RODIN, M. A new technique of pinealectomy for adult rats. Experientia, v.33, p.283-284, 1977.

MASSONE, F. (Ed). Anestesia veterinária: farmacologia e técnicas. In: Neuroleptoanalgesia e anesthesia dissociativa. Rio de Janeiro: Guanabara Koogan, 1994a. p.9297.

MASSONE, F. (Ed). Anestesia veterinária: farmacologia e técnicas. In: - Técnicas anestésicas de laboratório. Rio de Janeiro: Guanabara Koogan, 1994b. p.105-110.
MAGANHIN, C.C.; SIMÕES, R.S.; FUCHS, L.F.P. et al. Rat pinealectomy: a modified direct visual approach. Acta Cir. Bras., v.24, p.321324, 2009.

REITER, R.J.; SABRY, I.; NORDIO, M. et al. Rate of reproductive involution following either exposure to short days or dialy administration of melatonin is faster in inbred than in randon-bred female Surian hamsters. J. Endocrinol., v.120, p.489-96, 1989.

SOARES JÚNIOR, J.M.; BARACAT, E.C.; OLIVEIRA, S. et al. Influência da glândula pineal sobre a ingestão de água e $\mathrm{NaCl}$ em ratas normais e ooforectomizadas. Rev. Bras. Gincecol. Obstet., v.21, p.317-321, 1999.

TORTORA, G.J.; DERRICKSON, B. (Eds). O corpo humano: fundamentos de anatomia e fisiologia. In: As glândulas endócrinas. Porto Alegre: Artmed, 2012. p.328-356. 